Special Issue of the 6th International Congress \& Exhibition (APMAS2016), Maslak, Istanbul, Turkey, June 1-3, 2016

\title{
Role of Operational Radioprotection Simulation in the Dismantling of the Protection and Control Rods of VVR-S Reactor
}

\author{
I. Iorga ${ }^{a, b, *}$, R. Deju ${ }^{a}$, D. Gurau ${ }^{a}$ And M. $\operatorname{MincU}^{a}$ \\ ${ }^{a}$ Horia Hulubei National Institute of Physics and Nuclear Engineering, \\ POB MG-6, Magurele-Bucharest, 077125, Romania \\ ${ }^{b}$ Faculty of Physics, University of Bucharest, POB MG-11, Magurele-Bucharest, 077125, Romania \\ The VVR-S nuclear research reactor owned by Horia Hubulei National Institute of Physics and Nuclear \\ Engineering, has functioned between 1957 and 1997 at a nominal thermal power of 2 MW, using less-enriched \\ nuclear fuel (10\%), type EK-10, and highly enriched fuel (36\%), type S-36. The reactor control was carried out by \\ means of nine rods placed in the central part of the core. Four rods were used for the manual control of power, one \\ for automatic control, three rods for reactor safety (emergency rods) and one for the fine control of power. One of \\ the high hazard operations was the dismantling of the activated-contaminated control rods. Because of a higher \\ radiological risk, simulation was performed to determine the expected maximum dose. The maximum gamma dose \\ rate obtained using simulated results was $3.5 \mathrm{~Sv} / \mathrm{h}$, for the highly activated rod. In the real measurement, when \\ the work was performed, the maximum gamma dose rate was $3 \mathrm{~Sv} / \mathrm{h} .{ }^{90} \mathrm{Sr}+{ }^{90} \mathrm{Y}$ are expected to be present in the \\ control rods radioactivity.
}

DOI: 10.12693/APhysPolA.131.514

PACS/topics: 28.41.Te

\section{Introduction}

The nuclear research reactor, owned by Horia Hulubei National Institute for Physics and Nuclear Engineering (IFIN-HH), was the first research reactor using the VVR-S type soviet design. It was built between 1955 and 1957, in Romania. The reactor was used for research and for radioisotope production. VVR-S means that it is a thermal neutrons reactor, model S, moderately cooled and reflected with distilled water, fueled in the beginning with $10 \%$ enriched uranium and with $36 \%$ enriched uranium subsequently.

The research reactor had operated until 1997 and was permanently shut-down in 2002. During its life time, the installation was functional for a period of $113467 \mathrm{~h}$, including $2000 \mathrm{~h}$ at $3.0-3.5 \mathrm{MW}$ power. The total power output was up to $9.59 \mathrm{GWd}$ in 1997. It had a utilization factor of $65 \%$ (about 9510 effective days of operation), with an average of $1 \mathrm{MW}$ thermal power. The decommissioning of the reactor has started in 2010 and is planned to be finalized in 2020. It is the first nuclear research reactor from the South-East of Europe that has started the decommissioning project [1].

The reactor control was carried out by means of nine rods, placed in the central part of the core; 4 rods were used for the manual control of power, 1 for automatic control, 3 rods for reactor safety (emergency rods) and 1 for the fine control of power [1-2]. The dismantling of

\footnotetext{
*corresponding author; e-mail: johnny@nipne.ro
}

the activated-contaminated control rods was performed in the second phase of the research reactor decommissioning project. For this purpose, simulations were performed to evaluate the highest radiological risk that may arise during these processes. The ALARA regulatory requirement for all radiation protection programs needs to be followed, based on the minimization of radiation doses and limiting the release of radioactive materials into the environment, by employing all reasonable methods.

The risk acceptance criteria must be in conformity with the associated ALARA principles: (i) ALARP-a level of risk that is tolerable and cannot be reduced further without the expenditure of costs that are disproportionate to the benefit gained or where the solution is impractical to implement; (ii) AHLARP-As high/low as reasonably practicable; (iii) SAHARA-Safety as high as reasonably achievable. The cost benefit mitigation can be done only when risk acceptance criteria were intersected with the negative risk and resources used to accomplish the activity [3-8]. The radioactive waste streams were estimated by direct and indirect measurements. Thus, at the end of the decommissioning project, the radiation dose is estimated to be about $0.1 \mathrm{mSv} /$ year (as individual dose limit), for the release of the VVR-S nuclear facility from regulatory body control. As regards the radiation protection program, the radiation dose limit is $20 \mathrm{mSv} /$ year for the personnel professionally exposed, $1 \mathrm{mSv} /$ year for population and $10 \mu \mathrm{Sv} /$ year for the material freely released as the result of decommissioning $[9,10]$. The main purpose of the simulations was to ensure the radioprotection safety for the professional worker, who will make the dismantling works. 
The simulation takes in the account the time data when the activities were performed. The potential radionuclides in the reactor and the dose rate were mostly known.

\section{Protection and control rods system description}

Nuclear reactor active core has been designed to provide a nominal power of $2000 \mathrm{~kW}$, of a maximum and medium thermal neutrons flux of $2 \times 10^{13}$ and $10^{13} \mathrm{n} / \mathrm{cm}^{2} \mathrm{~s}$, respectively and it is a variant of the experimental reactor realized in the USSR with a higher power. The basics of building the active core of the VVR-S reactor were practically identical in both reactors, the main difference being that the fuel element sheath thickness was increased from $1 \mathrm{~mm}$ to $2 \mathrm{~mm}$ for the VVR-S reactor. Based on the similarity of these two reactors, critical dimensions calculation of the VVR-S was performed based on the experimental results obtained on nuclear reactor realized in former USSR [2].

Reactor control was realized with the help of nine rods, eight of which are from boron carbide and one from steel, arranged in the central part of active core. These nine rods had different roles: five were for manual power control (1PP1, 1PP2, 2PP1, 2PP2, LP), one for automatic control (AP) and three for emergency protection of reactor (AZ1, AZ2, AZ3). One of the five manual power control rods was the rod for the precision manual power control (LP). The manual power control rods had two parts united by a hinge, the inferior absorbing part, having a length of $600 \mathrm{~mm}$ and the superior part, made from steel, covered in aluminum sheath. Absorbing part was constituted from twenty small boron carbide $\left(\mathrm{B}_{4} \mathrm{C}\right)$ blocks inside of an aluminum sheath. Up and down movement of the control rods was made using a traction cable.

The automatic control rod was made using the same design, of two parts united by a hinge, similar to manual power control rods, with the difference that inferior part was constituted from a massive stainless steel cylinder in an aluminum tube. This constitutive had given us the major problem, concerning the operational radioprotection, during the time of dismantling activities [2]. The emergency protection of reactor rods was built in the same manner as the one for manual power control rods. In addition, these rods have acceleration devices, to reduce the time of there insertion in a failure case. Acceleration devices consist of a body that has an acceleration spring placed on a stem. For cable routing in the control rods channels, bridles were provided at the superior part of the reactor, that are connected with the channels. The power level of the reactor was controlled using seven ionizing chambers in the following order: (i) 1st chamber for power measurement at start-up; (ii) 1st chamber for automatic power recording; (iii) 2nd chamber for the automatic system to maintain power at the given level; (iv) 3rd chamber for the emergency protection system.

The control rods (1PP1, 1PP2, 2PP1, 2PP2, LP and $\mathrm{AP}$ ) were provided with transducers and position indicators and protection rods (AZ1, AZ2, AZ3) were provided with the turn signals for the end of the race. Signals were sent to control room. Unlike other channels, the channels afferent to protection rods (AZ1 and AZ2) were dry, without the distilled water circulation. The crash bar channel AZ3 was modified to permit the distilled water circulation [2]. In Fig. 1 photos and top view illustration of the control rods are presented.

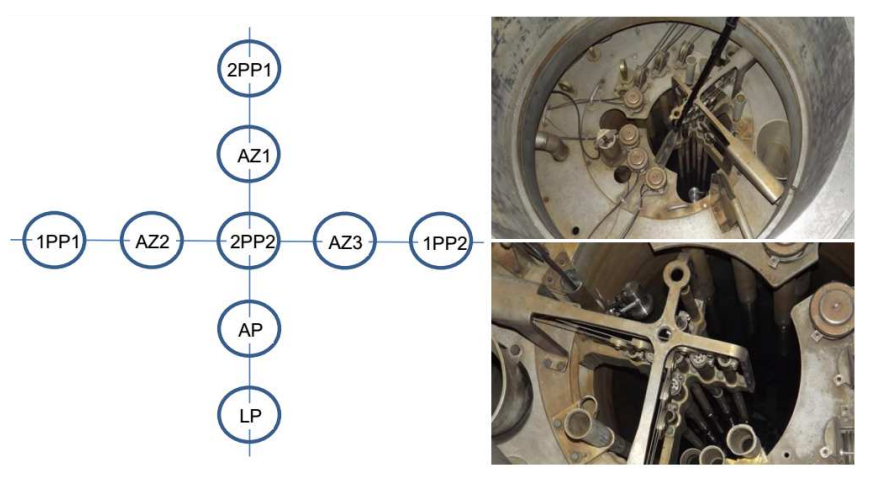

Fig. 1. Protection and control rods, top view.

\section{Strategies associated with radioactive waste characterization}

The characterization of the radioactive waste, resulted from the decommissioning of the VVR-S nuclear research reactor, for determining the physics, chemical and radiologic principal characteristics, had the following main objectives: (i) establishment of the radioactive waste treatment; determining the mode of the accomplishment of the safety and storage or disposal criteria; (ii) complexation or verification of the associated radioactive inventory. The radioactive waste from the decommissioning of the VVR-S nuclear reactor, like those from the dismantling of the protection and control rods system, has been divided in two categories: contaminated and activated materials.

Contamination occurs from corrosion and erosion of the activated particles, carried by the coolant and fuel irradiation and fission products. In addition, contamination can occur from leaking of the primary circuit, that processes and stores the radioactive effluents from fuel unloading operations and incidents of labor. Fission products can occur if the cooling circuit of the reactor fuel rods was damaged.

Activated materials are located in and around active core, which is the most active part of the reactor structure [11]. In the exposed reactor, to block a lower thermal neutron flux, the biological protection was used, which normally was made of heavy concrete, filled with screws. The main activation products are ${ }^{60} \mathrm{Co},{ }^{55} \mathrm{Fe}$ (hardly detectable), ${ }^{63} \mathrm{Ni}$ (hardly detectable), ${ }^{152} \mathrm{Eu}$ and ${ }^{154} \mathrm{Eu}$.

${ }^{60} \mathrm{Co}$ is the "key nuclide", because it is quickly revealed by gamma spectrometric measurements. Hardly detectable radionuclides activity is difficult to measure, but their activity can be correlated with the activity of other radionuclides. ${ }^{137} \mathrm{Cs}$ is the "key nuclide" for fission products 
and ${ }^{90} \mathrm{Sr}+{ }^{90} \mathrm{Y}$ and ${ }^{241} \mathrm{Am}$ for actinide group [1, 11]. In the case of hardly detectable radionuclides, specific and total activity can be calculated using the method of scaling factors, having as the reference ${ }^{60} \mathrm{Co}$ radionuclide (major activation product) and ${ }^{137} \mathrm{Cs}$ (fission product). To estimate correction factors, theoretical calculations, results from measurements of gamma spectrometry and literature data can be used [11]. In Table I the potential radionuclides involved in the contamination/activation of the protection and control rods, as part of the VVR-S structural components, are presented [1].

TABLE I

Possible radioactive contaminants of structural elements of the reactor block (including protection and control rods system), resulting from VVR-S operation.

\begin{tabular}{|c|c|c|c|c|c|c|}
\hline \multirow[b]{2}{*}{ Item } & \multirow[b]{2}{*}{ Radionuclide } & \multirow[b]{2}{*}{$\begin{array}{l}\text { Emitted } \\
\text { radiation }\end{array}$} & \multirow{2}{*}{$\begin{array}{c}\text { Life } \\
\text { time } \\
\text { [years] }\end{array}$} & \multicolumn{2}{|c|}{ Exclusion level } & \multirow[b]{2}{*}{ Observation/detection method } \\
\hline & & & & $\begin{array}{c}\Lambda_{\text {surf. }} \\
{[\mathrm{Bq} / \mathrm{g}]}\end{array}$ & $\begin{array}{c}\Lambda_{\text {spec. }} \\
{\left[\mathrm{Bq} / \mathrm{cm}^{2}\right]}\end{array}$ & \\
\hline \multicolumn{7}{|c|}{ Activation products } \\
\hline 1 & ${ }^{55} \mathrm{Fe}$ & EC, $\mathrm{X}$ & 2.7 & 300 & 30 & $\begin{array}{l}\text { Chemical separation }+ \text { spectrometry at low energies } \\
\text { (X-rays) }\end{array}$ \\
\hline 2 & ${ }^{63} \mathrm{Ni}$ & $\beta$ & 100 & 1000 & 70 & $\begin{array}{l}\text { Liquid scintillator with efficiency of } 75 \% \text { or scintillator } \\
\mathrm{NaI}(\mathrm{Tl}) \text { for qualitative analysis, efficiency } 0 \%+\text { correla- } \\
\text { tion factor of }{ }^{137} \mathrm{Cs} \text { and }{ }^{60} \mathrm{Co}\end{array}$ \\
\hline 3 & ${ }^{60} \mathrm{Co}$ & $\beta, \gamma$ & 5.3 & 3 & 1 & $\begin{array}{l}\text { Key radionuclide for activation products/gamma } \\
\text { spectrometry }\end{array}$ \\
\hline 4 & ${ }^{134} \mathrm{Cs}$ & $\beta, \gamma$ & 2 & 3 & 0.5 & Gamma spectrometry/have correlation factor with ${ }^{137} \mathrm{Cs}$ \\
\hline 5 & ${ }^{152} \mathrm{Eu}$ & $\mathrm{EC}, \mathrm{X}, \beta, \gamma$ & 13.5 & 10 & 7 & Gamma spectrometry \\
\hline 6 & ${ }^{154} \mathrm{Eu}$ & $\beta, \gamma, \mathrm{X}$ & 8.6 & 3 & 5 & Gamma spectrometry/have correlation factor with ${ }^{152} \mathrm{Eu}$ \\
\hline 7 & ${ }^{155} \mathrm{Eu}$ & $\beta, \gamma, \mathrm{X}$ & 4.76 & 30 & 30 & Gamma spectrometry/have correlation factor with ${ }^{152} \mathrm{Eu}$ \\
\hline 8 & ${ }^{166 m}$ Ho & $\beta, \gamma, \mathrm{X}$ & 1200 & 3 & 7 & Gamma spectrometry \\
\hline \multicolumn{7}{|c|}{ Fission product } \\
\hline 1 & ${ }^{90} \mathrm{Sr}+{ }^{90} \mathrm{Y}$ & $\beta$ & 28.7 & 3 & 0.4 & Beta-gamma global \\
\hline 2 & ${ }^{137} \mathrm{Cs}$ & $\beta, \gamma$ & 30 & 3 & 0.8 & $\begin{array}{l}\text { Key radionuclide for activation products/ gamma } \\
\text { spectrometry }\end{array}$ \\
\hline \multicolumn{7}{|c|}{ Actinide } \\
\hline 1 & ${ }^{241} \mathrm{Am}$ & $\alpha, \gamma$ & 432 & 0.3 & 0.05 & $\begin{array}{l}\text { Key radionuclide for actinide/ Global alpha beta analy- } \\
\text { sis / Gamma spectrometry for low energy. }\end{array}$ \\
\hline
\end{tabular}

Two methods can be used for radiological characterization of the waste: (i) destructive analysis, which can provide precise information about the radionuclides from the materials, (ii) non-destructive analysis, which is challenging because of the potentially high degree of variability from item to item. Because of the technical difficulties, the destructive methods cannot be applied at a large scale, because of the implied crumble of the material waste with increasing cost. The selection of the analysis methods was always based, in the first instance, on the knowledge of the radiological history of the characterized material. Thus, knowing the type of radionuclides present in the waste, on the basis of testing, the sensitivity targets can be calculated, that will serve during selecting appropriate methods for radiological characterization $[5,8]$.

\section{Results and discussion}

Simulation of the experimental data for preparation of the dismantling operations was made heuristically, based on the mathematical description model of the reactor power. It has taken into account the radionuclide contamination/activation library (see Table I) and the analysis performed in radiological characterization activities, taking into account reactor operating history and the timing of execution of the dismantling operations in the decommissioning activities $[5,6,12]$. For a more accurate determination of the level of radioactivity, direct measurements were made on protection and control rods, using direct or remote control. Measurements were made in the area, which we knew that will be certainly activated (because of positioning near active core), including the protection and the control rods, remaining under water in the basin core. Taking into account the radioactive inventory, recorded as a result of the reactor radiological characterization and using chemical composition of control rods, it was concluded that the greatest activation amount should be in the rod made of stainless steel. This can be seen in Fig. 2.

The main radionuclides which generate radioactivity are ${ }^{137} \mathrm{Cs},{ }^{60} \mathrm{Co},{ }^{132} \mathrm{Eu},{ }^{63} \mathrm{Ni}$ (ionization chambers 
AP activation data scanning

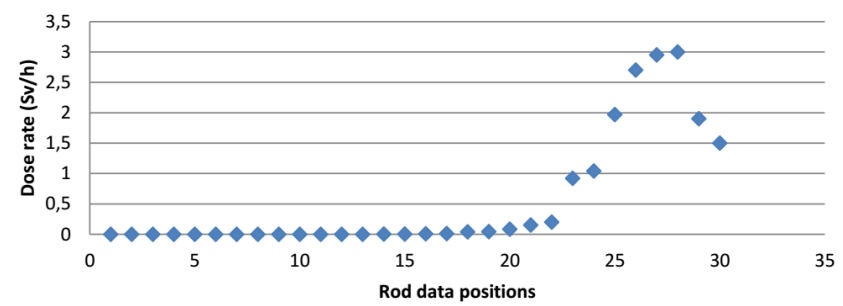

Fig. 2. Activation scan of the automatic control (AP) rod.

adjacent of the control bars and $\mathrm{Ni}$ from stainless steel rod), ${ }^{90} \mathrm{Sr}+{ }^{90} \mathrm{Y}$. Heuristic calculation has shown that the maximum value of gamma activity of automatic control $\operatorname{rod}(\mathrm{AP})$ is $3.5 \mathrm{~Sv} / \mathrm{h}$ and beta contamination (especially due to ${ }^{90} \mathrm{Sr}+{ }^{90} \mathrm{Y}$ ) is at most $31.25 \mathrm{kcps}$ (counts per second) over the background, which is equivalent to maximum value of $46.88 \mathrm{mSv} / \mathrm{h} \mathrm{cm}^{2}$. Calculation has taken into account the correlation factors in correspondence with main radionuclides ${ }^{137} \mathrm{Cs},{ }^{60} \mathrm{Co}$, considered to be in proportion of $30 \%$ and $60 \%$, other radionuclides activity being embedded in ${ }^{137} \mathrm{Cs}$ and ${ }^{60} \mathrm{Co}$.

During the dismantling of the protection and the control rods, comprehensive measurements were done to ensure the safety. For every rod, a significant growth of dose rate was registered in time of rising the rod from the reactor pool. The high dose rate was up to $3 \mathrm{~Sv} / \mathrm{h}$ on the AP automatic control rod. This high value was below our expectations, because of the possible error taken into account in calculation, to be sure that doses will be under the high value, for which we were prepared. Every manipulation in dismantling operation for these high dose rates was made remotely using the Brokk type robot and the bridge crane of the VVR-S research reactor. In the Table II the range values of the dosimetric and contamination measurements, made during the dismantling time, are presented, for every control rod, shown in Fig. 1.

TABLE II

Dosimetric and contamination range measurements of protection and control rods (at dismantling time).

\begin{tabular}{c|c|c|c|c|c}
\hline \hline \multirow{2}{*}{ Item } & \multirow{2}{*}{ Cod } & Description & \multicolumn{2}{|c}{ Dose rate $[\mathrm{Sv} / \mathrm{h}]$} & $\beta$ contamination \\
\cline { 3 - 5 } & LP & precision manual power control rod & $2.87 \times 10^{-7}$ & $1.09 \times 10^{-3}$ & $1300 \mathrm{kcps}$ \\
2 & $\mathrm{AP}$ & automatic control rod & $2.85 \times 10^{-7}$ & 3.00 & $31.25 \mathrm{kcps}$ \\
3 & $2 \mathrm{PP} 2$ & manual power control & $2.42 \times 10^{-7}$ & $1.02 \times 10^{-3}$ & $580 \mathrm{cps}$ \\
4 & $\mathrm{AZ1}$ & emergency protection of reactor & $6.42 \times 10^{-7}$ & $1.07 \times 10^{-3}$ & $7500 \mathrm{kcps}$ \\
5 & $2 \mathrm{PP} 1$ & manual power control & $3.85 \times 10^{-7}$ & $6.91 \times 10^{-4}$ & $1574 \mathrm{kcps}$ \\
6 & $1 \mathrm{PP} 2$ & manual power control & $6.72 \times 10^{-7}$ & $8.54 \times 10^{-4}$ & $1300 \mathrm{kcps}$ \\
7 & $\mathrm{AZ3}$ & emergency protection of reactor & $6.80 \times 10^{-7}$ & $4.00 \times 10^{-3}$ & $1500 \mathrm{kcps}$ \\
8 & $\mathrm{AZ2}$ & emergency protection of reactor & $9.20 \times 10^{-7}$ & $8.60 \times 10^{-1}$ & $1200 \mathrm{kcps}$ \\
9 & $1 \mathrm{PP} 1$ & manual power control & $6.20 \times 10^{-7}$ & $8.80 \times 10^{-4}$ & $1300 \mathrm{kcps}$ \\
\hline \multicolumn{2}{l}{ Background } & & $0.56 \mu \mathrm{Sv} / \mathrm{h}$ & & $24 \mathrm{cps}$
\end{tabular}

In Fig. 3 the activation for the activated part of the automatic control rod (AP) is presented. The high range of activation needed to be handled carefully to avoid the overexposure (for example, when activated rod is lifted in the air without biological shield protection).

\section{Conclusions}

The role of these simulation data was to estimate the risk associated with the dismantling of the protection and of the control rods and to find necessary actions which must be taken to prevent accidental exposure. Necessity of knowing the dose arising from gamma radiation and beta contamination were needed in particular for taking protection measures, both, at dismantling of the protection and control rods and at packaging them in $220 \mathrm{l}$ drums. These needed to be made in accordance with CNCAN (National Commission for Nuclear Activities Control) norms and regulation that specify that dose rate at the $220 \mathrm{l}$ drum wall should to be less then $2 \mathrm{mSv} / \mathrm{h} \mathrm{[6].}$

Thus, specific measures were taken by building thick protective casks suitable for dose reduction. For example using the ALARA and associated principles, AP rod has been segmented in appropriate parts and put in special $220 \mathrm{l}$ drums with over $15 \mathrm{~cm}$ thick concrete wall, steel tube and $1 \mathrm{~cm}$ lead shield. Role of the simulation data in the operational radioprotection at the dismantling time was to support the in-site dismantling team, to avoid unnecessary exposure risk at high doses. After the comparing the simulated data with the real data, it was concluded that the simulation was $85.71 \%$ confident and had not produces underestimated values. That means that from radioprotection point of view the data were confident and helped to known the real situation before the beginning of the real activity. Simulated data were necessary for confident planning of the 
AP activation data

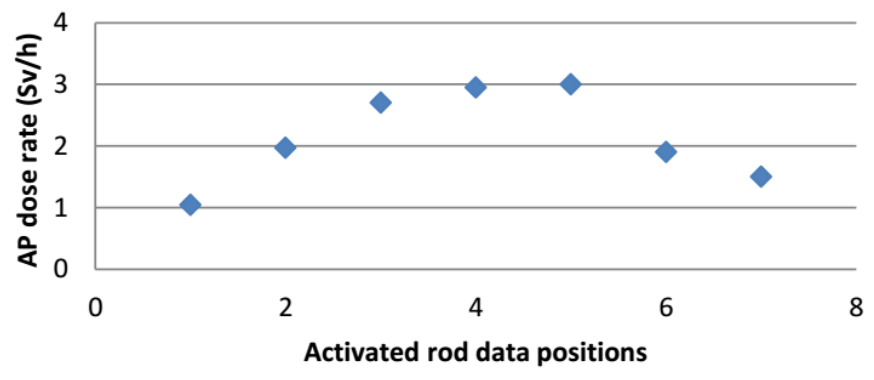

Fig. 3. Activation for the activated part of the automatic control rod (AP).

decommissioning activities of dismantling the protection and control rods system of the VVR-S nuclear research reactor from Magurele-Bucharest.

\section{Lesson learned}

In view of accomplishing the decommissioning activities with potentially high risks, it is advisable to make simulations that will give an idea about the implications, which can improve the safety and mitigate the risks. The radiological characterization data and research of scenarios that can overthrow the initial planning are very important. It can be tricky to accomplish the ALARA and associate principles, if from nowhere, in the middle of the activity, the dose rate will start quickly rising beyond the expected levels. The use of skilled and disciplined professionals is desirable to perform a risky and sensitive activity. It is important but not so easy to take the necessary measures. The knowledge of the operation history is very useful in the radiological characterization process. Simulation can be made and verified in the field, helping in planning and avoiding the unnecessary risks. When high dose rates are expected, it is recommended to evaluate/simulate the expected values to face unwanted events. The lifting of the automatic control rod (AP) using the same type of rod was simulated and an unusually high rotation of the rod was observed, that may prevent placing the rod in the collection funnel drum. That problem was solved by placing a bar near the linked wire to change the centre of gravity of the assembly, thus decreasing the angle of rotation, allowing the automatic control rod (AP) to enter in the collection drum.

\section{Acknowledgments}

The authors would like to express their deepest appreciation to all those who provided the possibility to complete this tasks. A special gratitude is given to the decommissioning dosimetry team, especially to Mr. Laurentiu Argatu, who diligently helped in gathering the necessary data. Furthermore, much appreciation is offered to the decommissioning team, who carried out the operations in the field.

\section{References}

[1] Plan de Dezafectare al Reactorului Nuclear de Cercetare VVR-S (Decommissioning Plan of the VVR$\mathrm{S}$ Research Reactor), M. Dragusin, V. Copaciu, V. Popa, C. Dragolici, I. Iorga, R. Deju, C. Mustata, C. Tuca, I. Mincu, ROM 04 029/2003, applicable revision.

[2] VVR-S RFS Reactor - VVR-S - Reactor Final Security Report.

[3] www.jakeman.com.au/media/as-high-or-low-asreasonably-practicable-ahlarp or www.31000risk.blogspot.com/.

[4] M. Dragusin, A.O. Pavelescu, I. Iorga, Nucl. Technol. Radiat. Protect. 26, 1451 (2011).

[5] IAEA Nuclear Energy Series No. NW-G-2.1, Policies and Strategies for the Decommissioning of $\mathrm{Nu}$ clear and Radiological Facilities, International Atomic Energy Agency, Vienna 2011.

[6] Technical Reports Series No. 446, Decommissioning of Research Reactors: Evolution, State of the Art, Open Issues, International Atomic Energy Agency Vienna 2006.

[7] Technical Reports Series No. 463, Decommissioning of Research Reactors and Other Small Facilities by Making Optimal Use of Available Resources, International Atomic Energy Agency, Vienna 2008.

[8] IAEA-TECDOC-1394 Planning, managing and organizing the decommissioning of nuclear facilities: lessons learned, International Atomic Energy Agency, Vienna 2004.

[9] M. Dragusin, R. Deju, V. Popa, I. Iorga, Decommissioning of the Nuclear Research Reactor VVR-S Magurele Bucharest Romania, (1 Sept. 2011).

[10] Normele Fundamentale de Securitate Radiologica Fundamental Norms on Radiological Safety (NSR01), CNCAN, Bucuresti 2002.

[11] E. Ionescu, D. Gurau, D. Stanga, O. Duliu, Rom. Rep. Phys. 64, 387 (2012).

[12] IAEA Nuclear Energy Series No. NW-T-1.18, Determination and Use of Scaling Factors for Waste Characterization in Nuclear Power Plants, International Atomic Energy Agency, Vienna 2009. 